\title{
On the Antifungal Effect of Benzoxazolinone and 6-Methoxybenzoxazolinone, Respectively, on Fusarium nivale
}

\author{
Ö. WAHLROOS and ARTTURI I. VIRTANEN \\ Laboratory of the Foundation for Chemical Research, Biochemical Institute, \\ Helsinki, Finland
}

\begin{abstract}
The decomposition of benzoxazolinone and 6-methoxybenzoxazolinone by Fusarium nivale, the adaptation of this fungus to benzoxazolinone, and the fungistatic or fungicidic action of benzoxazolinone on it has been investigated. The mode of inhibition of growth of $F$. nivale in media containing benzoxazolinone is discussed in relation to the results. The results suggest that benzoxazolinone has a fungistatic influence in a concentration $<0.5 \mathrm{mg}$ per $\mathrm{ml}$. In a concentration $>0.6 \mathrm{mg}$ per $\mathrm{ml}$ the fungicidic influence is already prevailing and the growth of Fusarium is totally inhibited.
\end{abstract}

The growth curves, shown in Fig. 1, are obtained when the biological activity of benzoxazolinone (BOA), the antifungal substance found in rye seedlings, is determined in an oat-glycerol solution or on agar plates, using different BOA concentrations and $F$. nivale as test organism.

A pronounced lag period is thus observed which is the longer the higher the BOA content. Even after a long period of time no growth was observed when the BOA concentration was higher than $0.5 \mathrm{mg} / \mathrm{ml}$.

Some experiments were performed in order to find out if the influence of BOA and 6-methoxybenzoxazolinone (MBOA) is fungistatic or fungicidic and to study the reactions underlying the lag period. In this paper these experiments and the results are described and discussed.

\section{DECOMPOSITION OF BOA BY F. nivale}

$40 \mathrm{mg}$ of BOA were added to $100 \mathrm{ml}$ of Czapek's nutrient solution containing $0.63 \mathrm{~g}$ of glycerol per litre and sterilized for $15 \mathrm{~min}$ under $0.8 \mathrm{~atm}$ pressure. Subsequently an amount corresponding to about $7 \mathrm{mg}$ dry weight of the mycelium of $F$. nivale, grown for 7 days at $20^{\circ} \mathrm{C}$ on oat-glycerol-agar, was added aseptically. The suspension in a 1 litre Erlenmeyer flask, closed by a cotton 
Fig. 1. Growth of the mycelium of $F$. nivale in a BOA containing oat-glycerol-medium. Curve numbers indicate the BOA content, $\mathrm{mg} / \mathrm{ml}$.

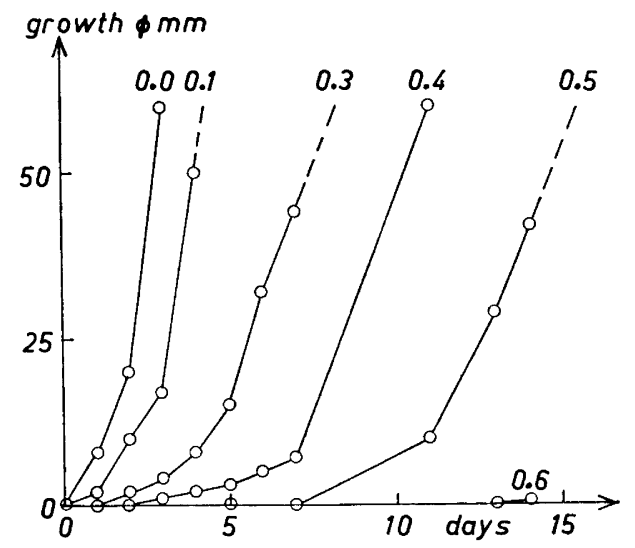

plug, was shaken in an automatical shaker at a frequency of 50 oscillations per min. A corresponding suspension without BOA was used as control. At intervals $1 \mathrm{ml}$ samples were taken with a sterile pipette. The samples were diluted to $100 \mathrm{ml}$, and the absorption at 230 to $300 \mathrm{~m} \mu$ was determined with a Beckman spectrophotometer. The BOA content was calculated from the

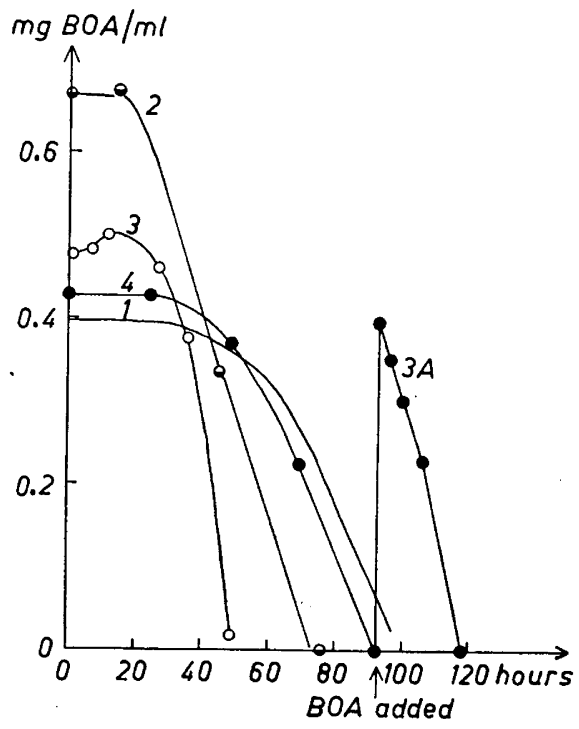

Fig. 2. Decomposition of BOA in a suspension of $F$. nivale in: 1 and 2 : Czapek solution; 3 and 4 : oat-glycerol solution. The numbers of curves 3 and 4 have changed places.

Acta Chem. Scand. 12 (1958) No. 1

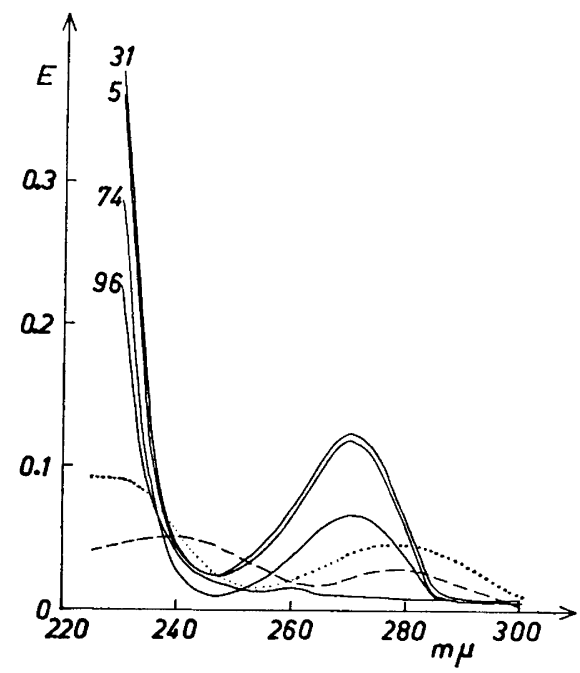

Fig. 3. UV-Spectra of the suspension of $F$. nivale in a Czapek solution containing BOA. Solid lines: vigorously shaken suspension. Curve numbers indicate test time in hours. Broken line: The spectrum of an unshaken suspension after decomposition of BOA. Dotted line: The spectrum of $o$-aminophenol in the same suspension. 


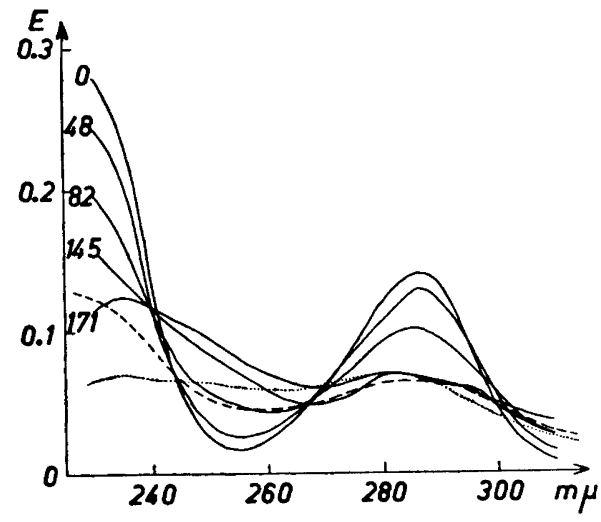

Fig. 4. Solid lines: The breakdown of MBOA effected by the mycelium of $F$. nivale in a vigorously shaken Czapek solution. Curve numbers indicate test time in hours. Broken line: 2-amino-5-methoxyphenol, partly oxidized in air. Dotted line: 2amino-5-methoxyphenol, further oxidized in air.

absorption maximum at $270 \mathrm{~m} \mu$. The weight of the mycelium was determined in $5 \mathrm{ml}$ samples. The results are shown in Fig. 3 and curve 1 in Fig. 2.

In another experiment, in which the $\mathrm{BOA}$ content was $0.67 \mathrm{mg}$ per $\mathrm{ml}$, and the amount of mycelium corresponded to about $70 \mathrm{mg}$ dry weight per $100 \mathrm{ml}$ solution, the BOA content decreased by $50 \%$ in $45 \mathrm{~h}$; after $76 \mathrm{~h}$ no BOA could be found in the test solution (Fig. 2, curve 2).

After $120 \mathrm{~h}$ a determination of BOA was made on the mycelium in $50 \mathrm{ml}$ test solution; $0.041 \mathrm{mg}$ of BOA was found, which is about $1 / 500$ of the amount of BOA added at the beginning of the experiment.

It is noticeable that in all experiments it took 20 to $30 \mathrm{~h}$ before the decomposition of BOA started. Does this lag period depend on an adaptive formation of a BOA-decomposing enzyme? To test this possibility a new portion of BOA was added to a suspension in which the originally added BOA was decomposed. As can be seen from curve $3 \mathrm{~A}$ in Fig. 2 the decomposition of BOA has now started immediately.

\section{DECOMPOSITION OF 6-METHOXYBENZOXAZOLINONE BY F. nivale}

The experiment was performed as above. The MBOA content of the solution was $0.4 \mathrm{mg}$ per $\mathrm{ml}$, and the amount of mycelium corresponded to about $90 \mathrm{mg}$ dry weight per $100 \mathrm{ml}$ solution.

After $170 \mathrm{~h}$ practically all MBOA had disappeared from the solution.

\section{CHANGES IN THE UV SPECTRUM DURING THE DECOMPOSITION OF BOA} AND MBOA BY F. nivale

The UV spectrum of the BOA solution with the mycelium of $F$. nivale had during the experiment the same shape as the spectrum of pure BOA solution, from which fact it can be concluded that aromatic decomposition products of BOA, possibly formed during the experiment, were hardly enriched in the solution (Fig. 3). When practically all BOA had disappeared a very weak maximum at $260 \mathrm{~m} \mu$ could be noticed. It disappeared rapidly, however. 
On performing the experiment without shaking, two new maxima (at 240 and $280 \mathrm{~m} \mu$ ) were observed when BOA had disappeared (Fig. 3).

In the MBOA solution with $F$. nivale mycelium two new maxima were observed at $235 \mathrm{~m} \mu$ and $282 \mathrm{~m} \mu$ after $125 \mathrm{~h}$ as well as an inflexion point at $295 \mathrm{~m} \mu$ which disappeared after $170 \mathrm{~h}$ when all MBOA was already decomposed (Fig. 4). In addition there was a maximum at $460 \mathrm{~m} \mu$. The change in the spectrum cannot be due to $\mathrm{pH}$-variations, since the $\mathrm{pH}$ remained constant during the experiment. It thus seems that one or more new compounds containing a benzene ring had been formed from MBOA by $F$. nivale.

In Figs. 3 and 4 are also seen the spectra of $o$-aminophenol and 2-amino-5methoxyphenol oxidized in the air. The latter compound also showed a maximum at $460 \mathrm{~m} \mu$. It is seen that the spectra do not quite correspond to the maxima observed in $F$. nivale suspensions during and after the disappearance of BOA and MBOA though there are certain similarities.

The rate of decomposition seems to depend on the amount of mycelium as well as on the original BOA concentration of the solution. MBOA seems to decompose slower than BOA. It ought to be mentioned that in an unshaken mycelium suspension BOA was no longer decomposed in a concentration of 0.5 to $0.6 \mathrm{mg} / \mathrm{ml}$.

\section{ADAPTATION OF $\boldsymbol{F}$. nivale TO BOA}

The lag period might thus be the time required by $F$. nivale to decompose BOA around the inoculate. Another possibility might be the adaptation of $F$. nivale to BOA. Therefore the following experiment was performed.

$\boldsymbol{F}$. nivale mycelium was transferred to 20 oat-glycerol-agar plates containing $0.6 \mathrm{mg}$ of BOA per ml. After 9 days growth could be seen on 12 plates. The mycelium grown on these plates was cultivated during 4 transfers on plates containing $0.6,1.0$, and $1.25 \mathrm{mg}$ of $\mathrm{BOA}$ per $\mathrm{ml}$. As early as during the second transfer $F$. nivale grew in the concentration $1 \mathrm{mg}$ per $\mathrm{ml}$. Even after the fourth transfer $F$. nivale did not grow in a higher concentration than this.

The observed length of the lag period at concentrations of 0.1 to $0.5 \mathrm{mg}$ BOA per $\mathrm{ml}$ can be supposed to depend on this weak adaptation.

\section{THE FUNGICIDIC INFLUENCE OF BOA AND MBOA ON $F$. nivale}

Nine days old mycelium of $F$. nivale was transferred to sterile $0.9 \%$ $\mathrm{NaCl}$ solutions containing different amounts of BOA. Each test tube contained $5 \mathrm{ml}$ solution and about $5 \mathrm{mg}$ dry weight of mycelium. At the contact times, shown in Table 1 , samples of the mycelium were separated, washed three times with sterile $0.9 \% \mathrm{NaCl}$ solution and then transferred to an oatglycerol-agar. Growth was followed during 7 days.

The results shown in Table 1 indicate that BOA has a fungicidic influence on $F$. nivale from a concentration of $0.5 \mathrm{mg}$ per $\mathrm{ml}$ upwards. In concentrations higher than this the fungicidic influence is comparatively rapid. MBOA also exerts a fungicidic influence on $F$. nivale at least in the concentration 0.5 $\mathrm{mg}$ per $\mathrm{ml}$ (contact time 6 days). 
Table 1. Growth of the mycelium of $F$. nivale after contact times of 1 to 33 days. Substrate in the growth tests oat-glycerol-agar.

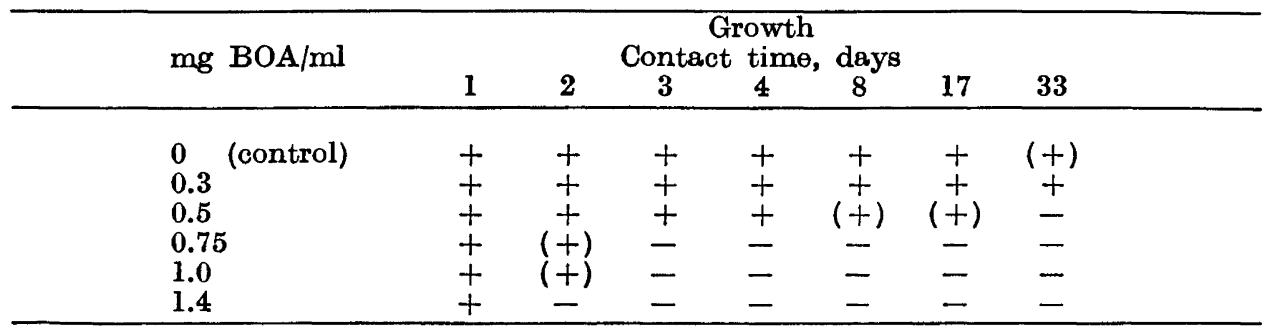

Marking of growth: $+=$ normal growth, $(+)=$ poor growth, $-=$ no growth.

\section{DISCUSSION}

On the basis of the observations reported above the growth of $F$. nivale in a nutrient solution or on agar plates containing BOA or MBOA could perhaps be explained in the following way: in a concentration up to $0.4 \mathrm{mg}$ per $\mathrm{ml}$ the influence is fungistatic, and the lag period depends on the adaptation of $F$. nivale to these substances. When growth has started, it at first proceeds slowly, and then accelerates to reach about the same rate as in a solution without BOA (Fig. 1). BOA determinations from growth flasks indicate that at this point $\mathrm{BOA}$ had practically disappeared from the media. In $0.5 \mathrm{mg}$ per $\mathrm{ml}$ there is already a weak fungicidal influence, the fungistatic one still prevailing, however. When the concentration rises to 0.6 or $0.7 \mathrm{mg}$ per ml, the fungicidic influence prevails, and growth is totally inhibited.

The chemical mechanism of the fungistatic and fungicidic influence of BOA and MBOA is still unknown.

As regards the way of the decomposition of $\mathrm{BOA}$ and $\mathrm{MBOA}$ by $F$. nivale it is possible that the corresponding aminophenols occur among the products, though, at least in the case of $\mathrm{BOA}$, the decomposition probably goes furtber.

The support given by the Rockefeller Foundation is gratefully acknowledged.

Received September 25, 1957.

Acta Chem. Scand. 12 (1958) No. 1 